\title{
CD4-Positive T Cell-Mediated Neuroprotection Requires Dual Compartment Antigen Presentation
}

\author{
Susanna C. Byram, ${ }^{1,2}$ Monica J. Carson, ${ }^{3}$ Cynthia A. DeBoy, ${ }^{1,2}$ Craig J. Serpe,${ }^{2}$ Virginia M. Sanders, ${ }^{4}$ and \\ Kathryn J. Jones ${ }^{1,2}$ \\ ${ }^{1}$ Department of Cell Biology, Neurobiology, and Anatomy, Loyola University Chicago, Maywood, Illinois 60153, 2Research and Development Service, Hines \\ Veterans Affairs Hospital, Hines, Illinois 60141, ${ }^{3}$ Department of Molecular Biology, The Scripps Research Institute, La Jolla, California 92037, and \\ ${ }^{4}$ Department of Molecular Virology, Immunology, and Medical Genetics, The Ohio State University, Columbus, Ohio 43210
}

Our laboratory discovered that $\mathrm{CD} 4$-positive $\left(\mathrm{CD}^{+}\right) \mathrm{T}$ cells of the immune system convey transitory neuroprotection to injured mouse facial motoneurons (FMNs) (Serpe et al., 1999, 2000, 2003). A fundamental question in the mechanisms responsible for neuroprotection concerns the identity of the cell(s) that serves as the antigen-presenting cell (APC) to activate the $\mathrm{CD}^{+}{ }^{+} \mathrm{T}$ cells. Here, we first establish that $\mathrm{CD}^{+}{ }^{+} \mathrm{T}$ cells reactive to non-CNS antigen fail to support FMN survival and, second, demonstrate a two-compartment model of CD4 ${ }^{+} \mathrm{T}$ cell activation. Mouse bone marrow (BM) chimeras were developed that discriminate between resident antigen-presenting host cell and BM-derived antigen-presenting donor cell expression of major histocompatibility complex II within central and peripheral compartments, respectively. After facial nerve transection, neither compartment alone is sufficient to result in activated CD4 ${ }^{+} \mathrm{T}$ cell-mediated FMN survival. Rather, $\mathrm{CD} 4{ }^{+} \mathrm{T}$ cell-mediated neuroprotection appears to depend on both resident microglial cells in the central compartment and a BM-derived APC in the peripheral compartment. This is the first in vivo report demonstrating a neuroprotective mechanism requiring APC functions by resident (i.e., parenchymal) microglial cells.

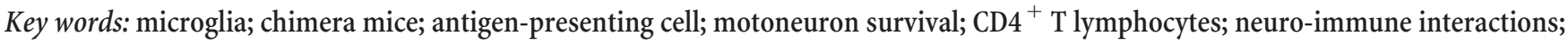
facial motoneuron

\section{Introduction}

Motoneuron cell death after injury or resulting from degenerative diseases such as amyotrophic lateral sclerosis (ALS) is a perplexing phenomenon for which investigators have highlighted many complex mechanisms required for motoneuron survival after nerve injury or during degenerative diseases (Sendtner et al., 1996; Jones et al., 1999; Wong et al., 2002). Although the CNS has historically been considered an immune-privileged site, insults to the nervous system elicit a range of immune-mediated responses that convey both deleterious and beneficial effects on the nervous system (Troost et al., 1989; Fu and Gordon, 1997; Serpe et al., 1999, 2000, 2003; Jones et al., 2002). Contrary to the CD4positive $\left(\mathrm{CD}^{+}\right) \mathrm{T}$ cell-mediated autoimmune processes that cause CNS damage (Huseby et al., 2001), our laboratory discovered an immune mechanism involving $\mathrm{CD} 4{ }^{+} \mathrm{T}$ cells that rescues facial motoneurons (FMNs) from axotomy-induced death (Serpe et al., 1999, 2000, 2003). Others have substantiated the neuroprotective effects of $\mathrm{T}$ cells after mechanical injury to the nervous system using various rodent and injury models (Moalem

Received Nov. 29, 2003; revised March 23, 2004; accepted March 24, 2004.

K.J.J. and V.M.S. were supported by National Institutes of Health (NIH) Grant NS40433. M.J.C. was supported by NIH Grants NS045735 and NS39508. We thank W. T. Lee for his generous gift of D011.10 spleens used in these studies. K.J.J. and V.M.S. share senior authorship. We declare that they have no competing financial interests.

Correspondence should be addressed to Dr. Kathryn J. Jones, Department of Cell Biology, Neurobiology, and Anatomy, Loyola University Chicago, 2160 South First Avenue, Maywood, IL 60153. E-mail: kjones1@lumc.edu. D01:10.1523/JNEUROSCI.5276-03.2004

Copyright $\odot 2004$ Society for Neuroscience $\quad$ 0270-6474/04/244333-07\$15.00/0 et al., 1999a,b; Hammarberg et al., 2000). The specific cells and components of the immune response to neuronal pathology that mediate beneficial versus deleterious effects remain unknown, but our basic understanding of the cells involved is crucial to the clinical management of neurological situations.

$\mathrm{CD}^{+}{ }^{+} \mathrm{T}$ cell activation and effector function requires an interaction between the antigen-restricted T cell receptor (TCR) of the $\mathrm{T}$ cell and major histocompatibility complex class II (MHC II)-displayed antigen on the surface of an antigen-presenting cell (APC) (Bretscher, 1992). Activated CD4 ${ }^{+} \mathrm{T}$ cells can potentially exert neurodegenerative actions, as demonstrated by the demyelination in multiple sclerosis or neuroprotective actions resulting in motoneuron survival after injury (Carson, 2002; Serpe et al., 2003). These discordant outcomes may result from varying environmental milieus, including different APCs, that regulate the $\mathrm{CD} 4{ }^{+} \mathrm{T}$ cell response. Three well characterized peripheral professional APCs exist: B cells, macrophages, and dendritic cells. CNS microglia can also present antigen and thus potentially serve as APCs (Aloisi, 2001; Carson, 2002). Facial nerve injury triggers both a peripheral response at the site of injury and a central response including the cell body and surrounding glia (Nissl, 1899; Lieberman, 1971; Fu and Gordon, 1997). Thus, there are two potential sites and populations of APCs that could influence $\mathrm{CD}^{+}{ }^{+} \mathrm{T}$ cell activation and subsequent effector function: a peripheral bone marrow (BM)-derived APC versus a central resident microglial APC.

The purpose of the current study was to determine whether 
$\mathrm{CD}^{+}{ }^{+} \mathrm{T}$ cell-mediated FMN survival is antigen specific and identify APCs that may facilitate CD4 ${ }^{+}$T cells to promote motoneuron survival after injury. Our results indicate that $\mathrm{CD} 4^{+} \mathrm{T}$ cells reactive to non-CNS antigen fail to support FMN survival and that $\mathrm{CD} 4{ }^{+} \mathrm{T}$ cells require activation in both the peripheral compartment (draining lymph node) and the central compartment (facial motor nucleus).

\section{Materials and Methods}

Animals. All mice used for the antigen-specificity studies were on the $\mathrm{BALB} / \mathrm{c}$ genetic background. Seven-week-old female wild-type (WT) and recombinase-activating gene-2 (RAG-2) knock-out (KO) mice (which lack functional $\mathrm{T}$ and $\mathrm{B}$ lymphocytes) were obtained from Taconic laboratories (Germantown, NY). Eight-week-old female DO11.10 TCR- $\alpha / \beta$-transgenic mice on the BALB/c genetic background (Murphy et al., 1990) were housed at the Wadsworth Center (Albany, NY), and splenocytes were provided by Dr. William T. Lee (Wadsworth Center, Albany, NY). All remaining experiments used mice on the C57BL/6 genetic background. Male and female WT, RAG-2 KO, and MHC II KO mice were obtained from Taconic laboratories. MHC II KO mice exhibit both a loss in MHC II expression on all cells and subsequently lack CD4 ${ }^{+}$ $\mathrm{T}$ cells.

$\mathrm{BM}$ chimeras were generated by using C57BL/6 (WT) and MHC II KO (C57BL/6 genetic background) BM injected at 5-10 $\times 10^{6}$ cells per recipient $4 \mathrm{hr}$ after 1200R irradiation. All chimeric mice were developed by M.J.C. and housed in the vivarium at the Scripps Research Institute (La Jolla, CA). Approximately 3 months after irradiation and BM transplant, chimera mice were provided to S.C.B. and housed in the veterinary medical unit at the Hines Veterans Affairs Hospital (Hines, IL).

All mice were housed and manipulated in accordance with institutional and National Institutes of Health guidelines, were provided autoclaved pellets and water ad libitum, and were housed under a $12 \mathrm{hr}$ light/dark cycle in microisolater cages contained within a laminar flow system to maintain a pathogen-free environment. After arrival, mice were permitted 1 week acclimation to their environment before experimental manipulation. All experimental manipulations were performed $\sim 4 \mathrm{hr}$ into the light cycle under aseptic conditions. Facial nerve axotomies were accomplished as described previously (Jones et al., 1985; Byram et al., 2003). The proximal and distal nerve stumps were separated, thereby preventing reconnection of the facial nerve. The left facial nerve was exposed but not transected, serving as a sham-operated internal control. Behavioral assessment for the completeness of the axotomy via inspection of eye-blink reflex and vibrissae movement was accomplished at the time of surgery and each week after the surgery until the animal was killed. Animals showing signs of incomplete transection were removed from data analysis. Experimental and control groups contained six to nine animals per group.

Source and preparation of $\mathrm{CD}^{+} \mathrm{T}$ lymphocytes. For the antigenspecificity experiments, donor $\mathrm{CD} 4{ }^{+} \mathrm{T}$ cells were enriched from either WT (BALB/c) or DO11.10 spleens as described previously (Byram et al., 2003). The donor naive and activated $\mathrm{CD}^{+}{ }^{+} \mathrm{T}$ cells used in the chimera experiments were all enriched from $\mathrm{WT}(\mathrm{C} 57 \mathrm{BL} / 6)$ mice. Naive CD4 ${ }^{+} \mathrm{T}$ cells were enriched from the inguinal and cervical lymph nodes of uninjured WT mice. Activated CD4 ${ }^{+} \mathrm{T}$ cells were enriched from the cervical lymph nodes and spleen $3 \mathrm{~d}$ after facial nerve axotomy. The appropriate naive or activated phenotype and level of enrichment was verified by fluorescence-activated cell sorting analysis using antibodies against CD4, CD62L, CD154, and CD44. CD4 ${ }^{+} \mathrm{T}$ cells ( $>95 \%$ enriched) were resuspended in PBS to $5.0 \times 10^{7}$ cells $/ \mathrm{ml}$, and $0.1 \mathrm{ml}$ was injected intravenously into the lateral tail vein of lightly anesthetized RAG-2 KO or chimera mice 1 week before axotomy. WT control mice subjected to axotomy were injected intravenously with $0.1 \mathrm{ml}$ of PBS into the lateral tail vein.

Immunohistochemistry. At $7 \mathrm{~d}$ after facial nerve transection, mice were deeply anesthetized with $3 \%$ halothane for $10 \mathrm{~min}$. The animals were killed by intracardial perfusion fixation with saline followed by $4 \%$ paraformaldehyde in $0.1 \mathrm{M}$ PBS, pH 7.4, and the brain was extracted. Brains were blocked coronally to include the facial nucleus and were then im- mersed in $4 \%$ paraformaldehyde at $4^{\circ} \mathrm{C}$ overnight followed by $0.2 \mathrm{M}$ phosphate buffer (no saline), pH 7.4, at $4^{\circ} \mathrm{C}$ overnight. Finally, the brains were equilibrated in $20-30 \%$ sucrose at $4^{\circ} \mathrm{C}$ for $1-3 \mathrm{~d}$ or until the brain tissue sunk to the bottom of the sucrose solution. Twelve to fourteen micrometer thick cryostat sections were collected throughout rostrocaudal extent of the facial nucleus.

Microglia were visualized using monoclonal antibodies to Mac-1 (complement receptor 3; Serotec, Kidlington, Oxford, UK) diluted 1:200 and incubated in secondary antibody (Ab), anti-rat biotinylated $\mathrm{IgG}$, followed by avidin-biotin complex (Elite kit; Vector Laboratories, Burlingame, CA) and chromagenic reaction with 3, 3'-diaminobenzidine. An IgG2b rat anti-mouse isotype control Ab (PharMingen, San Diego, CA) was used on sister sections at a dilution of 1:200.

FMN cell-counting procedure. At 4 weeks after facial nerve axotomy, mice were killed via $\mathrm{CO}_{2}$ asphyxiation, and the brains were rapidly frozen. Twenty-five micrometer thick cryostat sections were collected throughout the rostrocaudal extent of the facial motor nucleus. To determine the relative number of surviving FMNs after a facial nerve axotomy, cell profile counts were preformed as described previously (Serpe et al., 1999; Byram et al., 2003). Briefly, the sections were fixed in $4 \%$ paraformaldehyde and stained with thionin. The abducens nuclei and internal genu of the facial nerves were used to accurately match the location of the left (control) and right (transected) sides. Animal groups were coded by one investigator and subsequently analyzed under "blind" conditions by a second investigator who was unaware of the group divisions. Surviving FMNs containing a nucleus (see Fig. $1 a$, inset) were counted, and the percentage change between the left and right sides was calculated and compared between the two groups. The Abercrombie correction factor $(N=n \times T / T+D)$, where $N$ is the actual number of cells, $n$ is the number of nuclear profiles, $T$ is the section thickness (25 $\mu \mathrm{m})$, and $D$ is the average diameter of nuclei $(5 \mu \mathrm{m})$ (Coggeshall, 1992), was used to compensate for double counting in adjacent sections. Statistical analysis was accomplished using a one-way ANOVA (Sokal and Rohlf, 1981).

\section{Results \\ $\mathrm{T}$ cells reactive to non-CNS antigen fail to support FMN survival}

To determine whether $\mathrm{CD} 4{ }^{+} \mathrm{T}$ cell-mediated FMN survival requires a specific antigen, FMN survival levels were compared between WT control mice, non-reconstituted RAG-2 KO mice (lacking B and T cells), and RAG-2 KO mice reconstituted with enriched $\mathrm{CD}^{+}{ }^{+} \mathrm{T}$ cells from either WT or DO11.10 transgenic mice. DO11.10 transgenic mice express a transgenic TCR that exclusively recognizes a chicken ovalbumin peptide (OVA-323339) (Murphy et al., 1990). In all experiments described, FMN survival was analyzed at 4 weeks postoperative (WPO) and expressed as a ratio of control (unoperated) to axotomized (injured) side. In WT and RAG-2 KO mice, FMN survival was $87 \pm$ $3.0 \%$ (Fig. 1a,e) and $64 \pm 3.7 \%$ (Fig. 1b,e), respectively, and replicates that previously reported by Serpe et al. (2000). In RAG-2 KO mice reconstituted with WT-derived CD4 ${ }^{+} \mathrm{T}$ cells, FMN survival was $84 \pm 2.5 \%$ (Fig. $1 c$,e). In contrast, in DO11.10 transgenic $\mathrm{CD}^{+}{ }^{+} \mathrm{T}$ cell-reconstituted RAG-2 KO mice, FMN survival was $43 \pm 6.8 \%$ (Fig. $1 d, e$ ). Thus, $\mathrm{CD}^{+}{ }^{+} \mathrm{T}$ cells that were unable to recognize an antigen(s) associated with facial nerve injury failed to promote neuroprotection, indicating that CD4 ${ }^{+}$ $\mathrm{T}$ cell-mediated FMN survival may be antigen specific. Surprisingly, reconstitution with DO11.10-derived CD ${ }^{+}{ }^{+}$T cells led to an additional decrease in FMN survival that was significantly below that of non-reconstituted RAG-2 KO mice. The mechanisms responsible for this effect suggest a highly complex mechanism that is not well understood and is the focus of future investigations. 


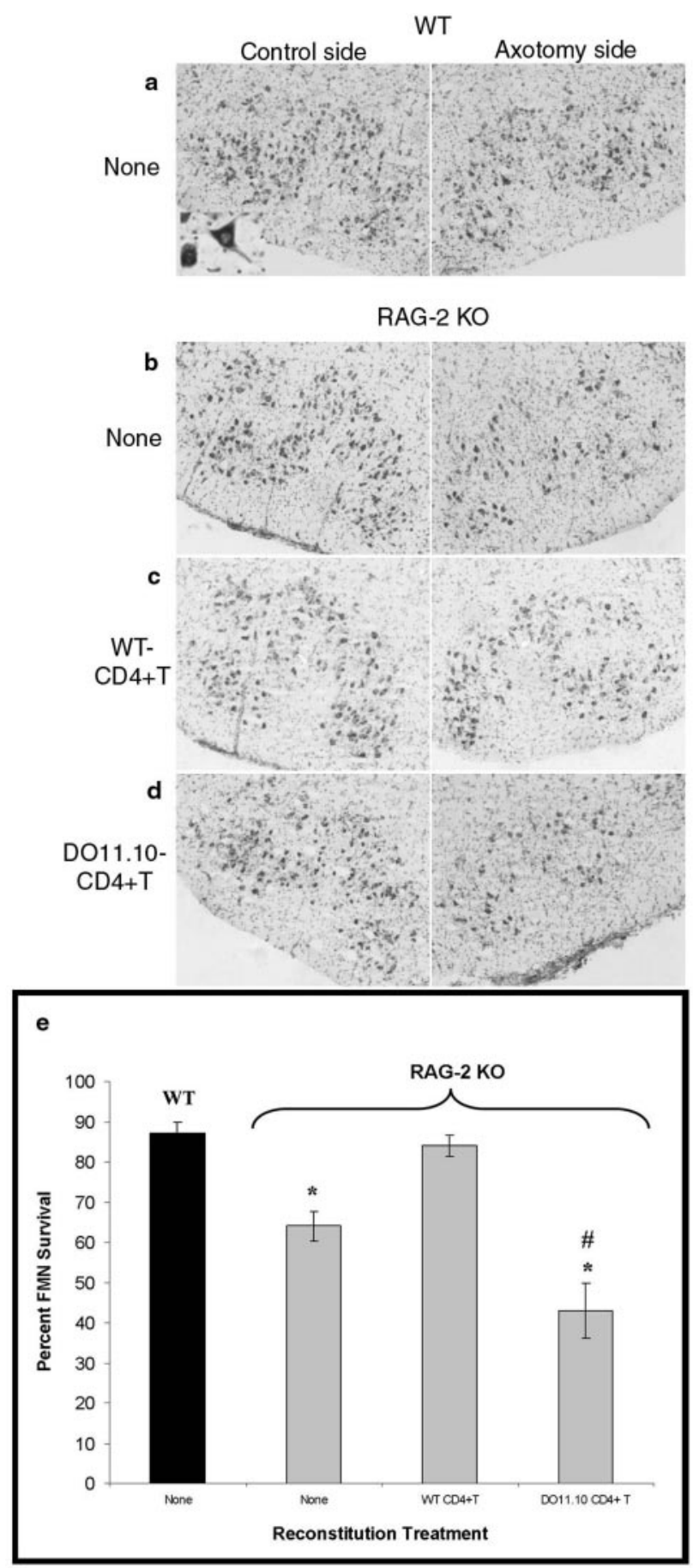

Figure 1. $\quad \mathrm{CD}^{+} \mathrm{T}$ cells reactive to non-CNS antigen fail to support FMN survival. $a-d$, Thioninstained FMNs of the control and axotomized facial motor nuclei 4 weeks after facial nerve axotomy $a$ WT mice without reconstitution (none); inset shows a thionin-labeled FMN with clear nucleus used for counting. b, RAG-2 KO without reconstitution (none). c, WT-derived CD4 ${ }^{+}$T cell-reconstituted (WT$\mathrm{CD}^{+}{ }^{+}$T) RAG-2 K0.d, D011.10-derived CD4 ${ }^{+}$T cell-reconstituted (D011.10 CD4 ${ }^{+}$T) RAG-2 K0.e, Average percentage survival \pm SEM of FMNs from right (axotomized) side of WT (black), RAG-2 KO (gray), WT-derived CD4 ${ }^{+} \mathrm{T}$ cell-reconstituted RAG-2 K0, and D011.10-derived CD4 ${ }^{+} \mathrm{T}$ cellreconstituted RAG-2 KO mice, relative to the unoperated left-side controls [the asterisk and the number sign represent a significant difference from WT (none) and RAG-2 KO (none), respectively, at $p<$ $0.01 ; n=6$ for all groups $]$.

\section{Microglia are present and reactive in MHC II KO mice}

Before directly addressing the potential role of microglia in FMN survival, it is important to determine whether immunodeficient mouse models used in these studies contain microglia and whether they react in the stereotypical manner after facial nerve transection. In all mice examined, ramified resting microglia were faintly stained with the Mac-1 Ab in the control (uncut) facial nucleus and, to an even lesser extent, in the surrounding hindbrain (Fig. 2a). In addition, $7 \mathrm{~d}$ after facial nerve injury, there was an activation of microglia as determined by Mac-1 upregulation in the axotomized facial nucleus in all mice examined, as qualitatively compared with the contralateral control side (Fig. 2b). Mac-1 staining in the injured facial motor nucleus increased markedly after axotomy, and this was accompanied by typical morphological changes such as cell body enlargement, shortening of processes, and loss of ramification. Moreover, Mac-1positive microglia cell bodies occasionally formed darkly labeled clusters (Fig. $2 b$ ). Importantly, these data demonstrate that microglia are both present in the immunodeficient mouse brain and capable of reacting to peripheral nerve injury.

BM-derived APCs are not sufficient to promote FMN survival In the present study, two chimera models (see supplemental Figure 1, available at www.jneurosci.org) were used to determine whether BM-derived APCs of the peripheral compartment and host APCs of the central compartment activate $\mathrm{CD} 4^{+} \mathrm{T}$ cells to mediate FMN survival. A right facial nerve axotomy was performed on WT control mice and MHC II KO chimeras (WT donor, MHC II KO recipient) to determine whether mice compromised for central APC function (through the loss of MHC II on resident host APC), but maintaining normal peripheral MHC II-positive APC, differ in FMN survival levels. In WT control mice, FMN survival was $86 \pm 1.6 \%$ (Figs. $3 a, 4$ ). In contrast, FMN survival in MHC II KO chimeras was $54 \pm 6.4 \%$ (Figs. $3 b, 4$ ). This cell survival is comparable with previously published data using RAG-2 KO mice (Serpe et al., 1999), indicating that there is no additional axotomy-induced cell death with the chimeric model of immune deficiency. The inability of MHC II KO chimeras to promote FMN survival was expected because the MHC IIdeficient thymus cannot support $\mathrm{CD}^{+}{ }^{+} \mathrm{T}$ cell maturation (known to be critical for mediating FMN survival) because of MHC II deficiency on thymic epithelial cells (which will not be replaced by WT donor $\mathrm{BM})$. Therefore, specific $\mathrm{CD} 4^{+} \mathrm{T}$ cell reconstitutions of the MHC II KO chimera mice were accomplished to determine whether donor-derived, MHC II-positive, $\mathrm{BM}$-derived APCs of the peripheral compartment alone can activate $\mathrm{CD} 4^{+} \mathrm{T}$ cells to mediate FMN survival.

All CD $4^{+} \mathrm{T}$ cell reconstitutions occurred 1 week before facial nerve axotomy. MHC II KO chimera mice received either naive or activated $\mathrm{CD} 4^{+} \mathrm{T}$ cells. Naive $\mathrm{CD} 4^{+} \mathrm{T}$ cells were enriched from the lymph nodes of uninjured WT mice. Activated (i.e., facial nerve antigen-primed) $\mathrm{CD} 4{ }^{+} \mathrm{T}$ cells were enriched from the cervical lymph nodes and spleen of WT mice $3 \mathrm{~d}$ after a facial nerve axotomy. Hence, the activated $\mathrm{CD} 4{ }^{+} \mathrm{T}$ cells were primed specifically to antigens derived from the facial nerve injury, whereas naive $\mathrm{CD} 4{ }^{+} \mathrm{T}$ cells have not seen FMN antigen. In MHC II KO chimeras reconstituted with naive $\mathrm{CD} 4{ }^{+} \mathrm{T}$ cells, FMN survival was $43 \pm 7.0 \%$ (Figs. $3 c$, 4). Similarly, in MHC II KO chimeras reconstituted with preactivated $\mathrm{CD} 4{ }^{+} \mathrm{T}$ cells, FMN survival was $44 \pm 8.5 \%$ (Figs. $3 d, 4$ ). These data indicate that donor MHC II-positive, BM-derived APCs alone are not able to promote $\mathrm{CD} 4{ }^{+}$T cell-mediated FMN survival in an MHC II KO animal. This suggests that another host APC, such as a parenchymal microglial cell that is resistant to irradiation and not replaced by a BM transplant, may be critical for mediating FMN survival after injury. 
FMN survival requires dual compartment antigen presentation A right facial nerve axotomy was performed on WT chimeras (MHC II KO donor, WT recipient) to determine whether mice compromised for BM-derived APC function (through the loss of MHC II on BM-derived APC), but maintaining normal MHC II-positive host APC function, differ in FMN survival. In WT chimeras, FMN survival at $4 \mathrm{WPO}$ was $55 \pm 6.5 \%$ (Figs. 3e, 4). Unlike MHC II KO chimeras, WT chimeras maintain MHC II-positive thymic epithelial cells that are resistant to BM irradiation. Therefore, WT chimeras develop a normal naive CD ${ }^{+} \mathrm{T}$ cell population after BM transplant. Alone, these data suggest that host MHC II-positive APCs are incapable of initiating CD4 ${ }^{+} \mathrm{T}$ cell-mediated FMN survival. However, to confirm these findings and to determine whether MHC II-positive host APCs can sustain activation of an already primed $\mathrm{CD} 4{ }^{+} \mathrm{T}$ cell, naive and activated $\mathrm{CD} 4{ }^{+} \mathrm{T}$ cell reconstitutions were accomplished as described above. In WT chimeras reconstituted with naive $\mathrm{CD} 4{ }^{+} \mathrm{T}$ cells, FMN survival was $53 \pm 6.0 \%$ (Fig. $3 f, 4$ ). In contrast, in WT chimeras reconstituted with preactivated $\mathrm{CD} 4{ }^{+} \mathrm{T}$ cells, FMN survival was $81 \pm 7.8 \%$ (Figs. $3 g$, 4). In summary, these data suggest that although MHC II-positive host APCs do not initiate CD4 ${ }^{+} \mathrm{T}$ cell activation, they can sustain a preactivated $\mathrm{CD} 4^{+} \mathrm{T}$ cell to promote FMN survival after axotomy.

\section{Discussion}

Altogether, these data suggest a two-compartment model of FMN survival after injury, such that a BM-derived peripheral $\mathrm{APC}$ is necessary to initiate $\mathrm{CD} 4{ }^{+} \mathrm{T}$ cell activation, whereas a resident host APC is necessary to reactivate $\mathrm{CD} 4{ }^{+} \mathrm{T}$ cells centrally. The peripheral compartment may be critical to assure the antigen specificity and immediate initiation of the $\mathrm{T}$ cell response. After a peripheral nerve axotomy, macrophages function to phagocytose neuronal debris distal to the site of trauma (Perry and Brown, 1992) and, subsequently, migrate to local lymph nodes and the spleen (Kuhlmann et al., 2001), where professional APCs can present neuroantigen and activate naive CD4 ${ }^{+} \mathrm{T}$ cells. Once activated, $\mathrm{CD} 4^{+} \mathrm{T}$ cells can recirculate in search of their cognate antigen. Concurrent with the peripheral compartment reaction, there is a robust activation of glial cells within the facial nucleus in the central compartment after peripheral nerve injury (Graeber et al., 1998; Kalla et al., 2001). Chemokine expression and adhesion properties change in the facial nucleus, events that are favorable for $\mathrm{CD} 4{ }^{+} \mathrm{T}$ cell accumulation in the facial nucleus (Jones LL et al., 1997; Kloss et al., 1999). We hypothesized that parenchymal microglial cells in close proximity to injured motoneurons present antigen centrally to $\mathrm{CD} 4{ }^{+} \mathrm{T}$ cells previously activated and expanded in the peripheral compartment to direct the neuroprotection to the cell body.

Although there are other potential APCs in the CNS (e.g., astrocytes, perivascular microglia, infiltrating macrophages), there are a number of arguments that direct our speculation that the parenchymal microglial cell acts as the central APC in this
WT MHC II KO RAG-2 KO
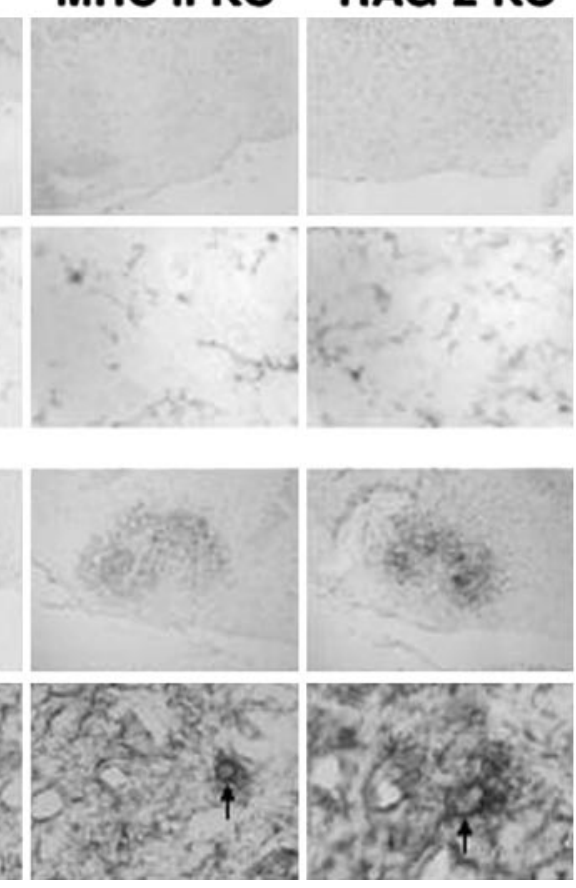

$40 x$

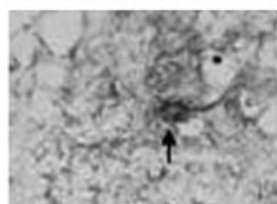

Figure 2. Immunohistochemistry of MAC-1-labeled microglia shows that microglia are present and reactive in $\mathrm{MHC}$ II KO mice. MAC-1-labeled microglia in the control and axotomized facial motor nuclei $7 \mathrm{~d}$ after facial nerve transection. $a$, Control side of WT, MHC II KO, and RAG-2 KO mice ( $4 \times$ and $40 \times$ magnification). b, Axotomized side of WT, MHCII KO, and RAG-2 KO mice ( $4 \times$ and $40 \times$ magnification). Arrows indicate phagocytic cluster.

model. First, irradiation BM chimera studies have demonstrated that parenchymal microglia, and not perivascular microglia or infiltrating macrophages, are long lived and rarely replenished by the donor BM (Hickey and Kimura, 1988). Thus, our model rules out the perivascular microglia and infiltrating macrophages as central compartment MHC II-expressing cells. Recall that CD $4^{+}$ $\mathrm{T}$ cell activation or reactivation requires an MHC II-expressing cell. The prevailing view is that astrocytes, although capable of expressing MHC II molecules in vitro, do not qualify as good APCs, because they fail to express costimulatory molecules and process protein antigen (Aloisi et al., 2000; Becher et al., 2000). Additionally, in the present model, astrocytes fail to express MHC II in vivo (Redwine et al., 2001). Although astrocytes might be playing a role as the MHC II-presenting cell in some diseases and insults, they are unlikely to be playing such a role here. Therefore, we speculate that the parenchymal microglial cell is the central compartment APC in our model.

A surprising finding from our initial study demonstrates significant FMN loss in the DO11.10-reconstituted animals. These data highlight the complex nature of immune responses within the CNS and, although they are outside the scope of the present study, they will be the focus of future investigations. However, this finding suggests that the DO11.10 CD $4{ }^{+} \mathrm{T}$ cell reconstitution may be toxic by being nonspecifically recruited into the CNS and acting in an undirected immune response. Thus, a non-antigenspecific response cannot be controlled by the resident APC and results in deleterious effects.

Interestingly, our model of facial nerve injury reveals three subpopulations of FMN with regard to cell death. Across all experimental groups, there is a significant population of FMNs that always survive, despite the loss of target-derived neurotrophic factors or immunodeficiency. In contrast, there is also a small population of neurons that always succumb to axotomy-induced 


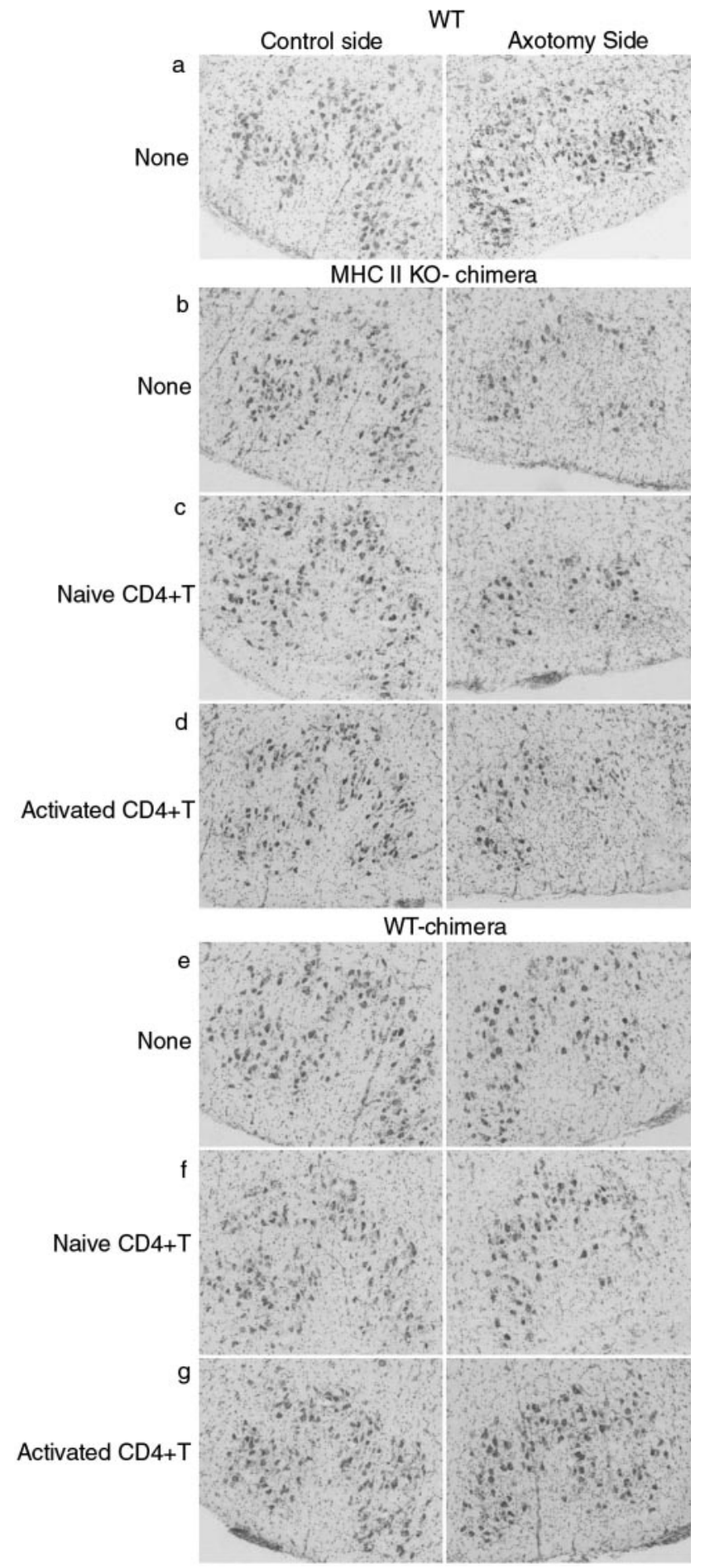

Figure 3. FMN survival requires both peripheral and central APC function. Thionin-stained FMNs of the control and axotomized facial motor nuclei 4 weeks after facial nerve axotomy. $a$, WT mice without reconstitution (none). $b$, MHC II KO chimera mice without reconstitution (none). c, Naive CD4 ${ }^{+} \mathrm{T}$ cell-reconstituted MHC II KO chimera mice. $d$, Activated CD4 ${ }^{+} \mathrm{T}$ cell reconstituted MHC II KO chimera mice. e, WT chimera without reconstitution (none). f, Naive $\mathrm{CD}^{+}{ }^{+} \mathrm{T}$ cell reconstituted WT chimera mice. $g$, Activated CD4 ${ }^{+} \mathrm{T}$ cell-reconstituted WT chimera mice.

cell death, regardless of the treatment group. Finally, $\mathrm{CD} 4{ }^{+} \mathrm{T}$ cells can rescue $\sim 30 \%$ of FMNs. The mechanisms responsible and the phenotype differences for the varying responses between these groups of FMNs are currently under investigation; however, the results from the present data lend some speculation.

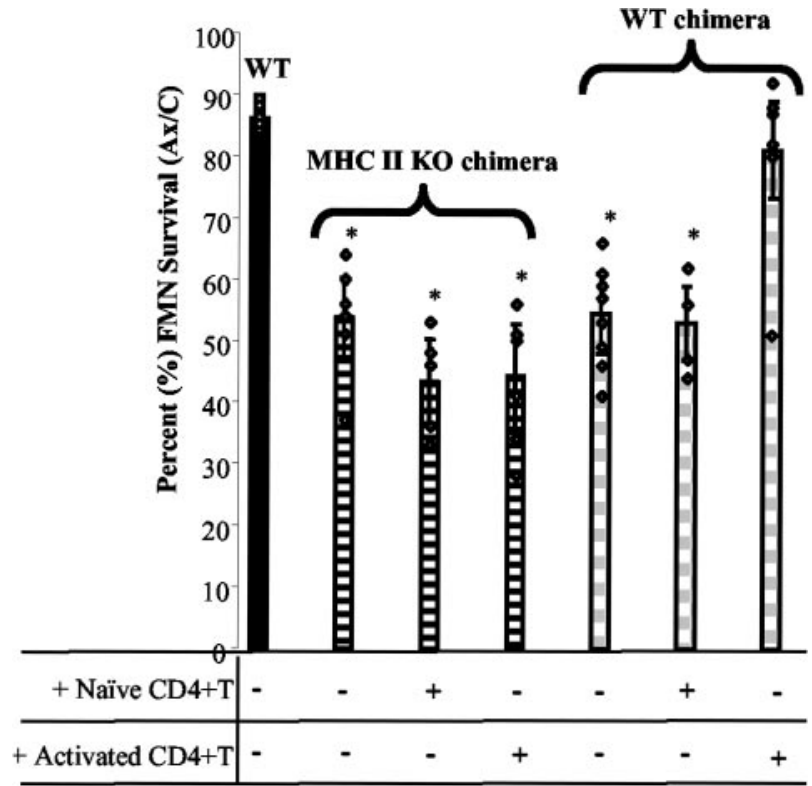

Figure 4. FMN survival requires both peripheral and central APC function. Average percentage survival \pm SEM of FMN srom right [axotomized (Ax)] side of WT (black), MHC II KO chimera (gray), and WT chimera (hatched) mice either without reconstitution ( - ) or with naive or activated $C D 4^{+} \mathrm{T}$ cell reconstitution $(+)$ relative to the unoperated left-side controls (C) (points represent individual animals in each group, and asterisks represent a significant difference at $p<0.001 ; n=6-9$ for all groups).

Previous reports have demonstrated that BM-derived perivascular microglial cells are sufficient to present antigen to $\mathrm{CD} 4^{+} \mathrm{T}$ cells, resulting in the autoimmune disease experimental allergic encephalomyelitis (Hickey and Kimura, 1988). In our study, BMderived APCs alone are not sufficient to promote FMN survival but also require a host APC. This is the first in vivo study that demonstrates an APC function for parenchymal microglial cells. Furthermore, this mechanism results in neuroprotection rather than neurodegeneration, suggesting functional differences between the subpopulations of microglial cells. Hence, the proximity of FMNs to the parenchymal versus perivascular microglia may account for the varying abilities for FMNs to survive or be rescued from axotomy-induced cell death. The extent of synaptic stripping, a well documented and robust response mediated by microglial cells after injury, also suggests that microglia may regulate spatial requirements for lymphocyte infiltration to mediate subsequent survival effects (Graeber et al., 1993; Jones KJ et al., 1997). In summary, the data presented here demonstrate a neuroprotective mechanism that involves a highly regulated, multistep process of antigen presentation that requires resident microglial cell APC function.

In the mouse facial nerve axotomy model, there are three critical events that support the hypothesis that microglial cells act as APCs to infiltrate $\mathrm{CD} 4{ }^{+} \mathrm{T}$ cells to promote FMN survival. First, in light of recent reports showing that activated $\mathrm{T}$ cells are recruited into the facial motor nucleus of mice after facial nerve transection (Raivich et al., 1998), it is likely that the T cell is involved in motoneuron survival after peripheral injury and may present its action at the level of the neuronal cell body. Second, there is neuronal cell death that coincides with the activation of phagocytic microglial cells (Streit et al., 1989; Raivich and Kreutzberg, 2000; Carson, 2002). These characteristics suggest that there is available neuronal debris for activated microglial cells to process and present as antigen to infiltrating $\mathrm{T}$ cells. Fi- 
nally, microglial cells characteristically respond to a peripheral nerve injury with the upregulation of MHC II, the expression of costimulatory molecules, and secretion of chemokines (Carson, 2002). All of these events point to a likely interaction between infiltrating $\mathrm{T}$ cells and antigen-expressing microglia that subsequently result in FMN survival mechanisms.

There are a few interesting parallels between established data in the literature and the data described here. Transient neuroprotection after peripheral injury has been demonstrated with the use of exogenous agents (Vejsada et al., 1998). This is particularly true in neonate animals where a large number of FMNs die after axotomy (Vejsada et al., 1998). Coincidently, published data from our laboratory suggest that the $\mathrm{CD} 4{ }^{+} \mathrm{T}$ cell response to FMN injury ultimately only provides transient motoneuron survival until target reconnection can occur (Serpe et al., 2000). Thus, it seems plausible to consider that the lack of a mature immune system in neonatal animals may account for the increased axotomy-induced motoneuron cell death demonstrated in these young animals (LaVelle and LaVelle, 1984; Haeney, 1994). Collectively, these data begin to suggest that cells of the peripheral immune system may be critical sources of survival factors in the initial stages of neuronal injury when the neuron has lost its target source of support (Serpe et al., 1999). Thus, an obvious direction for future studies to elucidate the potential mechanisms that result in $\mathrm{CD} 4{ }^{+} \mathrm{T}$ cell-mediated neuroprotection will include an assay of neuroprotective factors in our model.

Amyotrophic lateral sclerosis is a neurodegenerative disease that selectively leads to motoneuron death. Because the mechanism leading to motoneuron degeneration in ALS is not understood, currently there is no therapy available to prevent or cure ALS. The appearance of CD ${ }^{+} \mathrm{T}$ cells coinciding with activated microglia within the degenerating corticospinal tracts of ALS patients has fueled the hypothesis that ALS is an autoimmune disease. However, treatments that provide blanket immunosuppression have not provided benefits to patients with ALS. One interpretation for the conspicuous presence of $\mathrm{T}$ cells and activated microglia in ALS patients suggests that perhaps these cells attempt to serve as a positive role in motoneuron pathology as opposed to a destructive function. Such a theory has also been supported by a recent series of investigations suggesting that CNS autoimmunity may be beneficial after injury (Hauben et al., 2000).

Overall, the present data have demonstrated a highly regulated mechanism of $\mathrm{CD} 4{ }^{+} \mathrm{T}$ cell-mediated FMN survival that occurs in a multistep process, which involves primary activation in the periphery and subsequent microglial cell restimulation in the CNS. In future studies, we will address whether this activating interaction results in the release of a soluble trophic factor that rescues FMN from axotomy-induced death.

\section{References}

Aloisi F (2001) Immune function of microglia. Glia 36:165-179.

Aloisi F, Ria F, Adorini L (2000) Regulation of T-cell responses by CNS antigen-presenting cells: different roles for microglia and astrocytes. Immunol Today 21:141-147.

Becher B, Prat A, Antel JP (2000) Brain-immune connection: immunoregulatory properties of CNS-resident cells. Glia 29:293-304.

Bretscher P (1992) The two-signal model of lymphocyte activation twentyone years later. Immunol Today 13:74-76.

Byram SC, Serpe CJ, Pruett SB, Sanders VM, Jones KJ (2003) Natural killer cells do not mediate facial motoneuron survival after facial nerve transection. Brain Behav Immun 17:417-425.

Carson MJ (2002) Microglia as liaisons between the immune and central nervous systems: functional implications for multiple sclerosis. Glia $40: 218-231$.
Coggeshall RE (1992) A consideration of neural counting methods. Trends Neurosci 15:9-13.

Fu SY, Gordon T (1997) The cellular and molecular basis of peripheral nerve regeneration. Mol Neurobiol 14:67-116.

Graeber MB, Bise K, Mehraein P (1993) Synaptic stripping in the human facial nucleus. Acta Neuropathol 86:179-181.

Graeber MB, Lopez-Redondo F, Ikoma E, Ishikawa M, Imai Y, Nakajima K, Kreutzberg GW, Kohsaka S (1998) The microglia/macrophage response in the neonatal rat facial nucleus following axotomy. Brain Res 813:241-253.

Haeney M (1994) Infection determinants at extremes of age. J Antimicrob Chemother 34[Suppl A]:1-9.

Hammarberg H, Lidman O, Lundberg C, Eltayeb SY, Gielen AW, Muhallab S, Svenningsson A, Linda H, van Der Meide PH, Cullheim S, Olsson T, Piehl F (2000) Neuroprotection by encephalomyelitis: rescue of mechanically injured neurons and neurotrophin production by CNS-infiltrating $\mathrm{T}$ and natural killer cells. J Neurosci 20:5283-5291.

Hauben E, Butovsky O, Nevo U, Yoles E, Moalem G, Agranov E, Mor F, Leibowitz-Amit R, Pevsner E, Akselrod S, Neeman M, Cohen IR, Schwartz M (2000) Passive or active immunization with myelin basic protein promotes recovery from spinal cord contusion. J Neurosci 20:6421-6430.

Hickey WF, Kimura H (1988) Perivascular microglial cells of the CNS are bone marrow-derived and present antigen in vivo. Science 239:290-292.

Huseby ES, Liggitt D, Brabb T, Schnabel B, Ohlen C, Goverman J (2001) A pathogenic role for myelin-specific CD8(+) T cells in a model for multiple sclerosis. J Exp Med 194:669-676.

Jones KJ, Pfaff DW, McEwen BS (1985) Early estrogen-induced nuclear changes in rat hypothalamic ventromedial neurons: an ultrastructural and morphometric analysis. J Comp Neurol 239:255-266.

Jones KJ, Durica TE, Jacob SK (1997) Gonadal steroid preservation of central synaptic input to hamster facial motoneurons following peripheral axotomy. J Neurocytol 26:257-266.

Jones KJ, Coers S, Storer PD, Tanzer L, Kinderman NB (1999) Androgenic regulation of the central glia response following nerve damage. J Neurobiol 40:560-573.

Jones LL, Kreutzberg GW, Raivich G (1997) Regulation of CD44 in the regenerating mouse facial motor nucleus. Eur J Neurosci 9:1854-1863.

Jones TB, Basso DM, Sodhi A, Pan JZ, Hart RP, MacCallum RC, Lee S, Whitacre CC, Popovich PG (2002) Pathological CNS autoimmune disease triggered by traumatic spinal cord injury: implications for autoimmune vaccine therapy. J Neurosci 22:2690-2700.

Kalla R, Liu Z, Xu S, Koppius A, Imai Y, Kloss CU, Kohsaka S, Gschwendtner A, Moller JC, Werner A, Raivich G (2001) Microglia and the early phase of immune surveillance in the axotomized facial motor nucleus: impaired microglial activation and lymphocyte recruitment but no effect on neuronal survival or axonal regeneration in macrophage-colony stimulating factor-deficient mice. J Comp Neurol 436:182-201.

Kloss CU, Werner A, Klein MA, Shen J, Menuz K, Probst JC, Kreutzberg GW, Raivich G (1999) Integrin family of cell adhesion molecules in the injured brain: regulation and cellular localization in the normal and regenerating mouse facial motor nucleus. J Comp Neurol 411:162-178.

Kuhlmann T, Bitsch A, Stadelmann C, Siebert H, Bruck W (2001) Macrophages are eliminated from the injured peripheral nerve via local apoptosis and circulation to regional lymph nodes and the spleen. J Neurosci 21:3401-3408.

LaVelle A, LaVelle F (1984) Neuronal reaction to injury during development. In: Early brain damage, neurobiology, and behavior, pp 3-16. New York: Academic.

Lieberman AR (1971) The axon reaction: a review of the principal features of perikaryal responses to axon injury. Int Rev Neurobiol 14:49-124.

Moalem G, Monsonego A, Shani Y, Cohen IR, Schwartz M (1999a) Differential $\mathrm{T}$ cell response in central and peripheral nerve injury: connection with immune privilege. FASEB J 13:1207-1217.

Moalem G, Leibowitz-Amit R, Yoles E, Mor F, Cohen IR, Schwartz M (1999b) Autoimmune T cells protect neurons from secondary degeneration after central nervous system axotomy. Nat Med 5:49-55.

Murphy KM, Heimberger AB, Loh DY (1990) Induction by antigen of intrathymic apoptosis of CD4+CD8+TCRlo thymocytes in vivo. Science 250:1720-1723.

Nissl F (1899) Uber einige Beziehungen zwischen Nervenzellenerkrankun- 
gen und gliosen Erscheinungen bei verschiedenen Psychosen. Arch Psych 32:1-21.

Perry VH, Brown MC (1992) Role of macrophages in peripheral nerve degeneration and repair. Bioessays 14:401-406.

Raivich G, Kreutzberg G (2000) Inflammatory response following nerve injury. In: CNS regeneration (Ingoglia N, Murray M, eds), pp 287-314. New York: Marcel Decker.

Raivich G, Jones LL, Kloss CU, Werner A, Neumann H, Kreutzberg GW (1998) Immune surveillance in the injured nervous system: T-lymphocytes invade the axotomized mouse facial motor nucleus and aggregate around sites of neuronal degeneration. J Neurosci 18:5804-5816.

Redwine JM, Buchmeier MJ, Evans CF (2001) In vivo expression of major histocompatibility complex molecules on oligodendrocytes and neurons during viral infection. Am J Pathol 159:1219-1224.

Sendtner M, Holtmann B, Hughes RA (1996) The response of motoneurons to neurotrophins. Neurochem Res 21:831-841.

Serpe CJ, Kohm AP, Huppenbauer CB, Sanders VM, Jones KJ (1999) Exacerbation of facial motoneuron loss after facial nerve transection in severe combined immunodeficient (scid) mice. J Neurosci 19:RC7.
Serpe CJ, Sanders VM, Jones KJ (2000) Kinetics of facial motoneuron loss following facial nerve transection in severe combined immunodeficient mice. J Neurosci Res 62:273-278.

Serpe CJ, Coers S, Sanders VM, Jones KJ (2003) CD4+ T, but not CD8 + or $B$, lymphocytes mediate facial motoneuron survival after facial nerve transection. Brain Behav Immunol 17:393-402.

Sokal RR, Rohlf FJ (1981) Two-way ANOVA. In: Biometry, Ed 2, pp 299 337. San Francisco: Freeman.

Streit WJ, Graeber MB, Kreutzberg GW (1989) Peripheral nerve lesion produces increased levels of major histocompatibility complex antigens in the central nervous system. J Neuroimmunol 21:117-123.

Troost D, van den Oord JJ, de Jong JM, Swaab DF (1989) Lymphocytic infiltration in the spinal cord of patients with amyotrophic lateral sclerosis. Clin Neuropathol 8:289-294.

Vejsada R, Tseng JL, Lindsay RM, Acheson A, Aebischer P, Kato AC (1998) Synergistic but transient rescue effects of BDNF and GDNF on axotomized neonatal motoneurons. Neuroscience 84:129-139.

Wong PC, Cai H, Borchelt DR, Price DL (2002) Genetically engineered mouse models of neurodegenerative diseases. Nat Neurosci 5:633-639. 